\title{
Sağlık Alanı için Kişiselleştirilmiş Nesnelerin İnterneti Platformu
}

\author{
*Emine Sezer Murat Osman Ünalır Furkan Yıldız Akın Gümüşkavak Nuri Akçay \\ Ege Üniversitesi Mühendislik Fakültesi, Bilgisayar Mühendisliği Bölümü, 35030, Bornova, İzmir, Türkiye
}

\section{Özet}

Bireylerin doğumlarından önce başlayan ve hayatları boyunca devam eden temel ihtiyaçlarının başında sağlık hizmetleri gelmektedir. Teknolojinin insanlara sunduğu gelişmeler sonucunda medikal cihazlar sadece sağlık kurumları ve personeli tarafından değil, aynı zamanda bireylerin evlerinde kişisel olarak da kullanılmaya başlanmıştır. Hem bireylerin evde kullandıkları basit medikal cihazlar hem de sağlık kurumlarında verilen hizmetler nedeni ile durmadan büyüyen sağlık verisi üretilmektedir. Son yıllarda nesnelerin interneti (IoT) kavramı akıllı sistemler için yeni bir eğilim olmuştur. Bu çalışmada, kişilere özgü sağlık verileri, ölçümleri yapıldığı medikal cihazlardan akıllı telefonlara ve cihazlara, bu cihazlardan da buluta aktarımının gerçekleştirilmesi için geliştirilen sağlık alanına özel bir nesnelerin interneti platformu anlatılmaktadır. Böylece, kişiye özel sağlık verileri hasta mahremiyeti sağlanarak kayıt altına alınacak, sorgulanabilecek ve belirlenen kurallara göre verilerdeki sapmalar doğrultusunda kişiye ve/veya sorumlu kişiye ve kurumlara uyarı hizmetlerinin verilmesi sağlanacaktır. Ayrıca, geliştirilmiş olan platformda ilk olarak tansiyon ve nabız bilgiler işlenmiş ve bu bilgileri kullanarak kişisel sağlık hizmetleri ve alarmlar oluşturulmuştur.

Anahtar Kelimeler: Nesnelerin İnterneti (IoT), Sağlık Bilgi Sistemleri, Medikal Cihazlar, Sağlık Bilgisi, Bluetooth Düşük Enerj.

\section{A Personalized Internet Of Things Platform For Health Care}

\author{
*Emine Sezer Murat Osman Ünalır Furkan Yıldız Akın Gümüşkavak Nuri Akçay \\ Faculty of Engineering, Department of Computer Engineering, Ege University, 35030, Bornova, İzmir, \\ Turkey
}

\begin{abstract}
Health is one of the basic requirements of an individual that starts before the birth and continues through his lifelong. As a result of technological developments, medical devices have begun to be used not only in medical institutions by healthcare personnel, but also at individuals' homes. Big health data is continuously produced due to the simple medical devices that individuals use at home as well as services provided by health institutions. In recent years, the concept, of Internet of Things (IoT) has become a new trend for intelligent systems. In this paper, Personalized Internet of Things Platform for Health Care domain, which is developed in order to carry out personal health data from the medical devices to smart phones and devices where the measurements are made, and transfer to the cloud from these devices, is explained Thus, the private health data will be registered and inquired by providing patient privacy, and warning services will be provided to the person and responsible persons and institutions in accordance with the determined rules. Thus, the private health data will be recorded and inquired by providing patient privacy, and warning personal health care services will be provided to the person and/or responsible people and institutions according to the determined rules. In the developed platform, firstly the blood pressure and heart rate information are processed, and personal health services and alarms were created by using this information, also.
\end{abstract}

Key words: Internet of Things (IoT), Health Information Systems, Medical Devices, Health Information, Bluetooth Low Energy.

*Sorumlu Yazar: Adres: Mühendislik Fakültesi, Bilgisayar Mühendisliği Bölümü, Ege Üniversitesi, 35030, Bornova, İzmir, Türkiye. E-posta: emine.sezer@ege.edu.tr, Telefon: +902323392595 


\section{Giriş}

Geçmişten günümüze internet teknolojileri fark edilir bir büyüme içerisinde devam etmekte ve her geçen gün farklı ihtiyaçlar ve buna bağlı olarak da teknolojiler geliştirilmektedir. Bilgisayar, bilgi ve internet teknolojilerinin hızla büyümesi ve gelişmesi, insanların ve kurumların bu sistemlere olan bakış açısını değiştirmektedir. Bu teknolojilere olan bağlılık her geçen gün arttırmaktadır. Aynı zamanda, bilişim teknolojilerine bağlı bütün kavramları birbirine yakınlaştırmaktadır. Bu ihtiyaçlardan yola çıkılarak oluşturulan sistemlerin en başında Nesnelerin İnterneti (Internet of Things - IoT) gelmektedir.

IoT; sensörler, makineler ve akıllı cihazlar gibi fiziksel nesnelerin internete bağlanmasını, bağlı cihazlardan gelen verinin toplanmasını ve işlenmesini, işlenen veri sonucunda belirli iş süreçlerinin gerçekleştiriminin otomatik olarak yapılmasını hedeflemektedir. Kısacası, IoT ile uzaktan algılayıcı verisine erişmek ve uzaktan fiziksel dünyayı kontrol etmek mümkün olacaktır. Bu sistemde yerleşik sensörlü cihazlar ve nesneler, farklı cihazlardan gelen verileri birleștiren ve belirli ihtiyaçları karşılamak üzere oluşturulan uygulamalarla bu bilgiyi paylaşmak için belirli analitikler uygulayan Nesnelerin İnterneti Platformuna bağlıdır [1].

Birçok alan için sunulan hizmetleri ve süreçleri kolaylaştıracağı için önemli bir anlam ifade eden Nesnelerin İnterneti; çevre, tarım, enerji, kamu düzeni ve güvenliği, ulaşım ve sağlık gibi alanlarda hızla kullanılmaya başlanmıştır. Bu alanlarda yola çıkılarak oluşturulan akıllı evler, akıllı şehirler, akıllı filo yönetimi ve akıllı trafik kontrol sistemleri nesnelerin internetinin ilk kullanılmaya başlandığı ve başarılı sonuçlar verdiği sistemlerdir.

Sağlık alanında nesnelerin interneti ile ilgili ilk kullanım örnekler uzaktan izleme, akıllı sensörler ve tıbbi cihaz entegrasyonu gibi uygulamalarda görülmeye başlanmıştır. Sadece hastaları güvende ve sağlıklı tutmanın değil, aynı zamanda sağlık personelinin bakım verme şeklini iyileştirme potansiyeline sahip olması da nesnelerin internetinin sağlı alanında kullanımına teşvik edici bir etkendir. Sağlık alanındaki IoT destekli cihazlar ile hastalar doktorları ile daha çok iletişime girebilmekte, daha fazla bilgi akışı sağlanmaktadır. Bunun sonucunda hasta-doktor etkileşiminin daha fazla olması sağlanarak, hasta katılımı ve memnuniyeti artmaktadır. Ancak, sağlık bilgi sistemlerinde bu uygulamaların etkin bir şekilde gerçekleştirilebilmesi için bazı problemlerin çözülmesi gerekmektedir. Bağlanan cihazların sayısı ve topladıkları yüksek miktarda veri, Sağlık Bilgi Teknolojileri bölümünün yönetmesi gereken bir zorluk ama aynı zamanda oldukça önemli bir süreç olarak öne çıkmaktadır [2, 3]. Ayrıca, bu büyük miktardaki veriler hastaların anlık takiplerini zorlaştırabilmekte ve buna bağlı olarak da sağlık personelinin bu takipleri izlemesinde güçlük çekmelerine yol açabilmektedir.

Bu bildiride, sağlık alanı için son yıllarda kullanımı hızla artan IoT teknolojilerinden yola çıkarak düzenli tansiyon ölçümü yapılması gereken hastaların sağlı personelinin belirlediği aralıklarla tansiyonlarının ölçülmesi, ölçülen verilerin bulutta saklanması, kritik durumlarda bilgilendirme yapılabilmesi, hastaların ve doktorların gerekli analizleri görüntüleyebilmesi için sağlık alanına özel bir nesnelerin interneti platformunun gerçekleştirimi anlatılmaktadır. 
Çalışmanın organizasyonu şu şekildedir: ikinci bölümde sağlık alanında IoT kavramı ilgili literatür çalışmaları ile verilmektedir. Üçüncü bölümde geliştirilen platform için kullanılan teknolojilere kısaca değinilmektedir. Dördüncü bölümde, platformun gerçekleştirimi ile oluşturulan prototip anlatılmaktadır. Son olarak ise, yapılan çalışmanın sonuçları ve gelecek çalışmalara yer verilmektedir.

\section{Literatür Çalışması}

Nesnelerin İnterneti (Internet of Things - IoT); doğrudan kullanıcı müdahalesine gerek olmadan cihazların veya makinelerin, birbirleri ile veri iletebildiği, iletilen veriler ile belirli iş kuralları çerçevesinde kararların verildiği bir ağ yapısı olarak tanımlanabilir. IoT'nin sağlık hizmetleri ile ilgili uygulamaları; nesnelerin ve insanların (hasta veya personel) takibi, kimlik tanımlama ve doğrulama, otomatik veri toplama ve uzaktan algılama olarak özetlenebilmektedir. [4, 5, 6].

Akıllı Giyilebilir Hasta Takip Sistemleri (AGS), nesnelerin interneti kapsamında sağlık alanında kullanılan ilk örnekler olmuşlardır. Hastayı 7/24 izlemek ve gerekli durumlarda uyarmak üzere tasarlanmış sistemler olan AGS'ler son on sene içerisinde yaygınlığını arttıran ve hayatı kolaylaştıran etmenler olarak gündelik hayatlarımıza dahil olmakta ve sayıları da hızla artmaktadır [7]. PwC'ın (Price Waterhouse Coopers) 2014 yılında Amerika' da yapmış olduğu araştırmaya göre katılımcıların \%56'sı on sene içerisinde AGSler'in kullanımına bağlı olarak ortalama yaşam süresinin artacağını, \%46'sı ise beslenme ve egzersiz faaliyetlerini kontrol etmesi ile obezitenin önüne geçilebileceğini düşünmektedir [8].

Sağlık alanında kişisel sağlık kontrollerinde temel olarak yapılan testlerin başında tansiyon ölçümü ve nabız sayımı gelmektedir. Tansiyon kısaca kan basıncı olarak tanımlanabilir. Damarlardaki kan, dolaşım sırasında bir basınç oluşturmakta, bu basınç alınan gıda, yapılan iş ve harcanan güçle bağlantılı olarak gün içinde ufak sapmalar gösterebilmektedir. Sağlık alanında kan basıncı (veya tansiyon) iki ölçümle ifade edilmektedir: Sistolik basınç ya da halk arasındaki adı ile büyük tansiyon ve Diyastolik basınç ya da halk arasındaki adı ile küçük tansiyon [9].

Dünyada ve ülkemizde ölümle sonuçlanan vakaların başında kardiyak aciller bir başka deyişle kalp ile ilgili acil durumlar yer almaktadır. Kardiyak acillerde zamanında ve etkin acil bakım uygulayabilmek çok önemlidir. Kalp rahatsızlığı en kısa sürede tanımlanabilmeli, tedaviye yönelik çalışmalar başlatılmalı ve en yakın sağlık merkezi ile koordinasyon sağlanıp, hastanın en yakın sağlık kurumuna transferi yapılmalıdır. Bu kapsamda kalp hastalıklarının tanımlanması sürecinde yoğun kullanılan parametrelerin ölçümü için donanımsal bileşenler EKG cihazı, nabız ölçer ve tansiyon ölçer gibi cihazlardır. [10] çalışmasında; nabız ölçer cihazı, donanımsal ve yazılımsal olarak gerçekleştirilmiştir. Hastadan elde edilen nabız verileri bulut sistemine hastanın geçmiş kayıtları olarak kayıt edilmiş ve analiz edilmiştir. Bu analizler sonucunda acil durumların otomatik olarak sistem tarafından tespiti ve ilgili yerlere bildirimi gerçekleştirilmiştir.

\section{Kullanılan Teknolojiler ve Yöntemler}

Sağlık alanı için kişiselleştirilmiş nesnelerin internet platformunun geliştirilme amacı, farklı sağlık IoT cihazlarının bir arada bulunabileceği, bu cihazlardan gelen verilerin bulutta saklanması, 
gerektiğinde hastanın ve doktorun bu verilere erişimi, gelen verilerin analizi sonucunda oluşabilecek acil durumlar için doktorun, hastanın ve sağlı merkezinin uyarılması aynı zamanda doktorun alarmlar kurarak, hastanın takibi üzerinde anlık değişiklikleri yapabilmesini sağlamaktır.

Platformun geliştirilmesi için farklı yazılımlar, veritabanları ve teknolojiler araştırılmıştır. Geliştirilecek platformun hem hastalar hem de doktorlar tarafından istenilen her yerde istenilen zamanda kullanılabilmesi için bir mobil uygulama üzerinden servis vermesi sağlanmıştır.

Sistemin ilk prototipi, Android işletim sistemi üzerinde gerçekleştirilmiş, bunun için Android yazılım geliştirme ortamı olan Android Studio [11] kullanılmıştır. Android Studio'da programlama dili olarak ise nesne tabanlı programlamayı destekleyen Java dili kullanılmıştır. Android, Google, Open Handset Alliance ve özgür yazılım topluluğu tarafindan geliştirilmiş açık kaynak kodlu bir mobil işletim sistemidir. Desteklenen uygulama uzantısı ".apk" dır.

Geliştirilen yazılım GitHub [12] üzerinde saklanmıştır. Git versiyon kontrol sistemi, yazılımcıların iş birliği içinde çalışması açısından esneklik sağlamakta, aynı zamanda yazılım üzerinde yapılan değişiklerin izlenmesini kolaylaştırmaktadır.

Prototip için IoT sağlık bileşeni olarak tansiyon aleti kullanılmıştır. Bluetooth Low Energy sistemiyle çalışmakta olan ticari bir marka seçilmiştir. "Bluetooth Smart" olarak da anılan BLE, klasik Bluetooth'un bir alt grubudur ve Bluetooth 4.0 temel özelliklerinin bir parçası olarak tanıtılmaktadır [13]. Özel bir uygulama ile cihazdan gelen sinyal tanınmaktadır. Uygulama cihazı bulutta depolanan bir eylem veya içerik parçasına bağlamakta ve kullanıcının görüntülemesini sağlamaktadır. Telefon ya da tabletteki ya da bilgisayardaki uygulama düzenlenerek, sinyaller karşısında nasıl tepki vereceği düzenlenebilmektedir. Kan basıncına ilişkin ölçüm gerçekleştirildikten sonra alınan verinin formatı [14] belirtimindeki şekilde elde edilmektedir. Cihazdan gelen veriler bu formata göre ayrıştırılmaktadır.

Veritabanı ve gerekli verilerin saklanması için Google tarafından geliştirilmiş olan Firebase platformu kullanılmıştır. En büyük avantajı, Android ortamıyla çok uyumlu bir şekilde çalışabilmesi ve kaynak erişiminin çok fazla olmasıdır [15]. Firebase, ücretsiz kullanım olanağının yanı sıra, uygulama yönetimi, kullanım takibi, veri depolama, bildirim gönderme gibi işlemleri, başka bir sunucuya veya sunucu taraflı kod yazmaya gerek kalmadan desteklemektedir.

\section{Sağlık Alanı için Kişiselleştirilmiş Nesnelerin İnterneti Platformu}

Sağlık Alanı için Kişiselleştirilmiş Nesnelerin İnterneti Platformu, hastalar ile doktorlar arasındaki etkileşimi kolaylaştırmayı hedefleyen, 7/24 erişime ve iletişime olanak tanıyan bir platform olarak tasarlanmıştır. Kişiye ait sağlık verileri üzerine ölçümler yapan nabız ölçerler, tansiyon aletleri, adım sayarlar, şeker ölçen cihazlar gibi bir çok medikal cihaz sadece sağlık hizmeti veren kurumlarda değil aynı zamanda hem hastaların evlerinde hem de üzerlerinde bulunabilmektedir. Bu durumda sürekli bir sağlık verisi üretilmektedir.

Hastalardan gelen bu verilerin olası acil durumlar için hayati önem taşıma olasılı̆̆g her zaman söz konusudur. Şekeri oldukça yüksek çıkan bir kişi şeker komasına girebilir ya da tansiyonu 
yükselmekte olan bir kişinin kalp krizi riski oluşabilir. Bu gibi durumlar için medikal cihazlardan gelen veri hastadan sorumlu olan doktor için oldukça önem taşımaktadır.

Bu amaç ile tasarlanan platformun arka-yüz ve ön-yüz geliştirme süreçleri tamamlanmıştır.

\subsection{Arka-yüz, Geliştirilmesi}

Arka yüz geliştiriminin ilk aşamasında sistemin bel kemiği olan veritabanı, bildirim ve depolama hizmeti sağlayan Firebase platformu kurulumu gerçekleştirilmiştir. Firebase'in sağlamış olduğu hizmetler oluşturulan Android projesine entegre edildikten sonra kullanıma hazır hale getirilmiştir.

Android Studio geliştirme ortamında nesne tabanlı Java programlama dili kullanılarak Firebase'in ve Bluetooth Low Energy'nin tüm avantajlarından faydalanılmıştır. MVC(Model-ViewController) yazılım geliştirme mimarisi temel alınarak model sınıfları ve Firebase ile iletişime geçen Firebase sınıfları oluşturulmuştur. Platformun prototipine ait Java sınıfları ve paket yapısı Şekil 1'de gösterilmektedir.

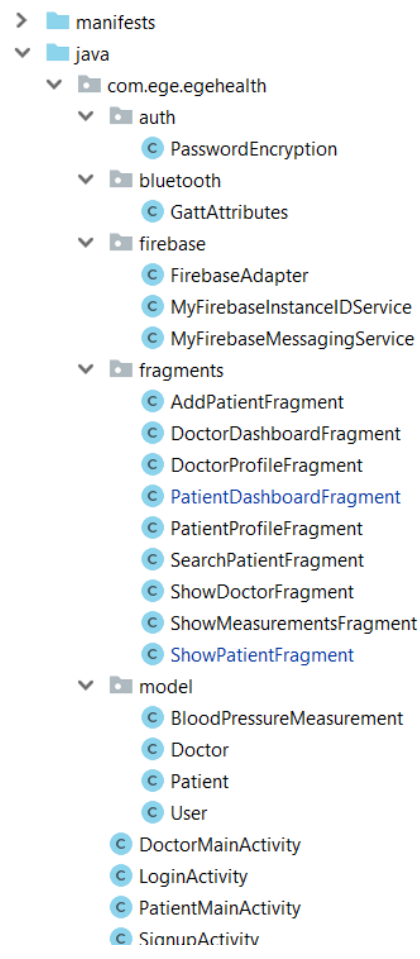

Şekil 1. Platformun paket yapısı ve sınıfları

Firebase paketi altında oluşturulan FirebaseAdapter sınıfı arka yüz işlemlerinin çoğunu gerçekleştirmektedir. Ana sınıflarda singleton tasarım deseni kullanılarak oluşturulan FirebaseAdapter sınıfi; Firebase Real-Time veritabanına, Firebase Notification hizmetine ve Firebase Storage hizmetine erişimi sağlamaktadır. Platform için oluşturulan Firebase Real-Time veritabanı yapısı Şekil 2'de gösterilmektedir. 


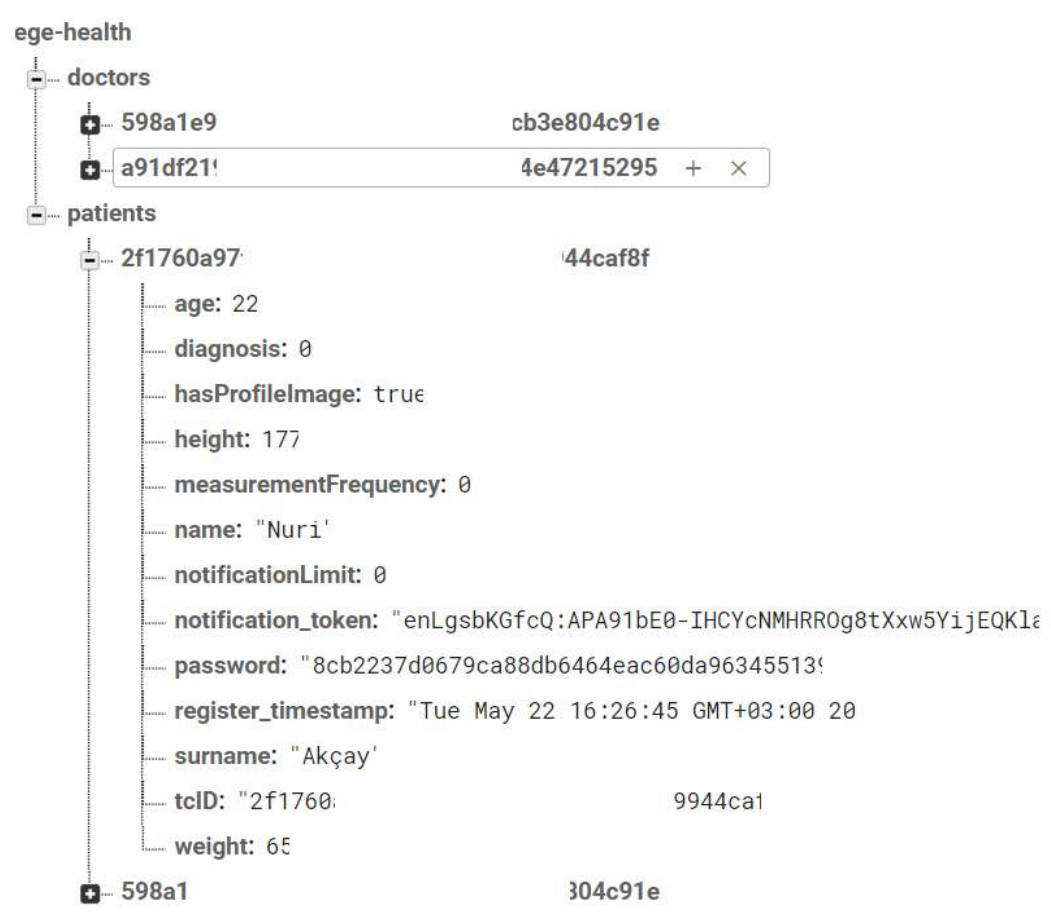

Şekil 2. Platformun Firebase Real-Time Veritabanı yapısı.

\section{2. Ön-yüz Geliştirilmesi}

Platformun geliştirilen prototipinde hastanın evinde kullanmakta olduğu tansiyon aletinden alınan ölçüm verileri, cep telefonundaki uygulamaya, bu uygulamadan da buluta aktarılmaktadır. Bu veriler, hem hasta tarafından hem de hastanın tedavi sürecinden sorumlu doktor tarafindan görüntülenebilmektedir.

Uygulama indirildikten sonra öncelikle Platforma kayıt olunması gerekmektedir. Kayıt işlemi sırasında birey sisteme "Doktor" ya da "Hasta" profillerinden birini seçerek Şekil 3 (a)'daki ekrandan kayıt işlemini gerçekleştirmektedir.

Kayıt ekranından sonra Platforma giriş için gelen ekrandan TC Kimlik Numarası ile giriş yapılmaktadır. Bireyin hem doktor hem de bir hasta olabilmesi söz konusu olduğu için, giriş ekranından yine kullanıcı tipi Şekil 3 (b)’deki ekranda görüldüğü gibi seçilmelidir.

Birey hasta olarak giriş yaptığında kendine ait kişisel bilgilerinin yanı sıra, düzenli olarak yapılan cihazdan gelen geçmiş sağlık ölçümlerinin değerlerini Şekil 4 'teki şekilde görebilmektedir. Ayrıca, hasta kendini ekleyen doktoru görüntüleyebilmekte eğer herhangi bir doktor kendini hasta olarak eklemediyse bile kişisel sağlık takibini platform üzerinden yapabilmektedir. Hastayı bir doktorun eklemesi durumunda ise bu durum hastaya uygulama tarafindan bir mesaj ile bildirilmektedir. 


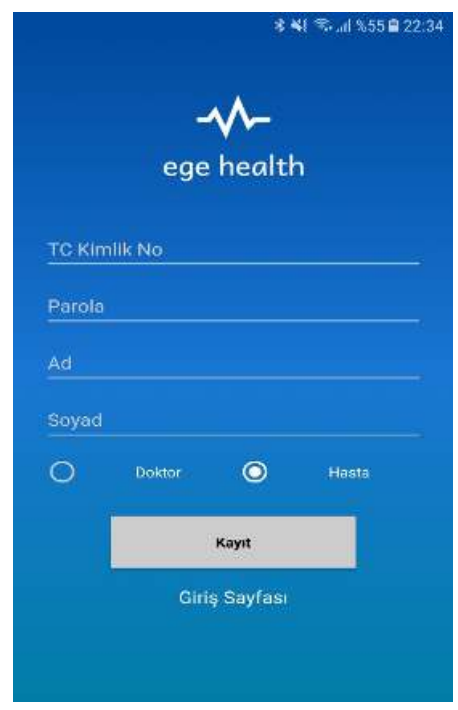

(a) Kayit olma

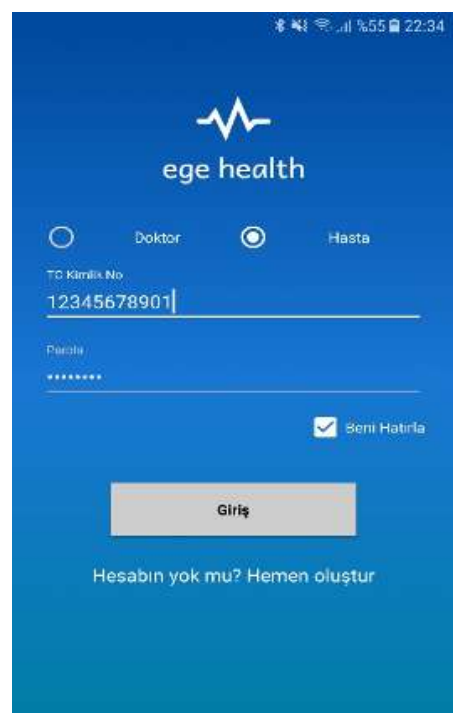

(b) Giriş yapma

Şekil 3. Platforma ilişkin ekran görüntüleri.

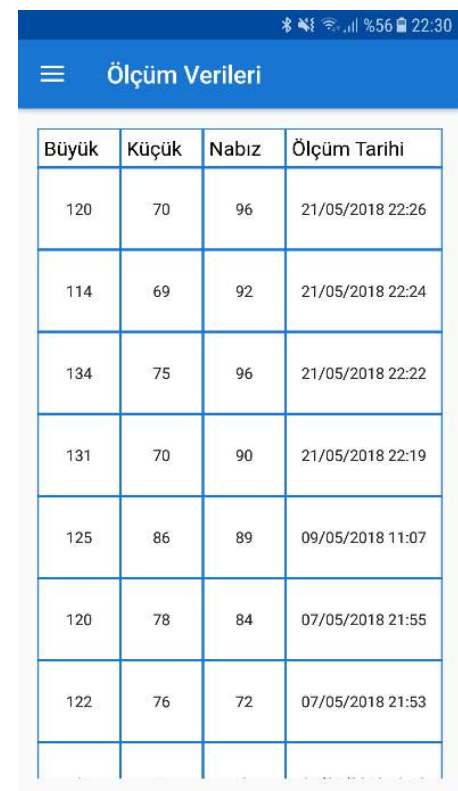

Şekil 4. Bir hastanın kişisel ölçüm verilerini görüntüleme ekranı.

"Doktor" kullanıcı tipi ile yapılan girişlerde, bir doktor kendi eklediği hastaların listesini görebilmektedir. Bu hastalardan herhangi birini seçerek, hastaya ait geçmiş ölçüm verilerini de kontrol edebilmektedir. Doktorlara ve hastalara ilişkin sistemin sunduğu en önemli özellik doktorun belirleyebileceği alarm değerlerdir. Bir doktor, izlemekte olduğu hastanın ölçüm 
değerleri için bir üst sınır belirleyebilir. Bu üst sınır değerine ulaşıldığında, platform tarafından doktora uyarı bildirimi gönderilmektedir. Uyarı bildirimi sonucunda, doktor hastasından ölçüm sıklığını arttırması yönünde platform üzerinden bir uyarı mesajı göndermektedir. Bu şekilde hastada devam edebilecek ve risk oluşturabilecek durumlar uzaktan kontrol edilip, erken önlem alınması için kolaylaştırıcı bir etken oluşturabilecektir.

\section{Sonuçlar}

$\mathrm{Bu}$ bildiride sağlık alanını için geliştirilen kişiselleştirilmiş nesnelerin interneti platformunun geliştirilme süreci ve ilk prototipin özellikleri anlatılmaktadır. İlk prototipte tansiyon ölçümünü anlık olarak yapmak isteyen kişilere ve hastalarının anlık ölçümlerini takip etmek ve ölçümlerin limitlerini ve sıklığını çeşitli durumlara göre düzenlemek isteyen doktorlara yönelik, mobil uygulama olarak çalışan, herkesin kullanımına açı bir sistem geliştirilmiştir. Gerçekleştirilen adımlar kısaca aşağıdaki gibi özetlenebilir:

> Sistemin Geliştirilmesi: Sağlık Alanı İçin Kişiselleştirilmiş Nesnelerin İnterneti Platformu üzerinden sunulacak hizmetler için, uygulama dili olarak Java programlama dili kullanılmıştır. Platformun gerçekleştirme ortamı olarak Android Studio kullanılmıştır. Veritabanında her bir doktorun ve hastanın verileri ayrı olarak tutulmakta, ayrıca her bir doktorun hangi hastalara sahip olduğu bilgisi burada güvenlik sınırları çerçevesinde saklanmaktadır. Veriler, Firebase Real-Time veritabanının sağladığı depolama servisi üzerinde saklanmaktadır. Tansiyon ölçümü için Bluetooth Low Energy destekli ticari bir tansiyon aleti kullanılmış ve cihazın uygulamayla olan bağlantısı Bluetooth 4.0 ile birlikte gelen Bletooth Low Energy teknolojisiyle gerçekleştirilmiştir. Hasta ve doktor arasındaki ilişki bahsedilen Firebase teknolojisinin Notification servisi sayesinde sağlanmaktadır. Bu sayede hastalar ve doktorlar yapılan işlemler için anlık olarak bildirim alabilmektedir.

$>$ Sistemin Sinanması: Sistem geliştirildikten sonra oluşabilecek her türlü duruma göre test edilmiştir. Kullanıcı hataları nedeniyle geri alınamayacak derecede büyük kayıplara yol açacak işlemler olmadığı görülmektedir.

Sağlık alanında geliştirilen ve nesnelerin internetini içeren bu sistem, hastaların evlerinde gerçekleştirdikleri ölçümlere ilişkin verilerin yeniden kullanılabilirliğini sağlamakta, aynı zamanda birlikte çalışabilirliği desteklemektedir. Türkçe arayüz sunan platform, özellikle yaşlı hastaların kullanımını kolaylaştırmaktadır. Bu platform ile hem doktorların hem de hastaların günlük hayattaki işlemlerini kolaylaştıracak ve aralarındaki ilişkiyi güçlendirecek bir yaklaşım izlenmiştir.

Platform tarafından sunulan sınır değerleri aşma durumundaki bildirim özelliği, anında müdahaleyi kolaylaştırmakta ve hayati önem taşıyan durumların biraz da olsa önüne geçilebileceği düşünülmektedir.

Platformun daha sonraki süreçlerinde adım sayıcı, akıllı tartı, şeker ölçüm cihazları gibi farklı ölçüm cihazlarının uygulamaya dahil edilmesi düşünülmektedir. Bu aşamadan sonra doktor ve hasta arasındaki ilişkiyi daha da arttıracak, sisteme gelen veriler sonucunda tedavi öneri mekanizmaları uygulamaya dahil edilebileceği düşünülmektedir. Ayrıca, sağlık kurumlarındaki 
daha farklı ölçümlerin de sisteme eklenmesinin sağlanmasıyla, hastane, tıp merkezleri gibi sağlık kuruluşlarında da yaygın bir şekilde kullanımı söz konusu olabilecektir.

\section{Kaynaklar}

[1] Clark J. What is the Internet of Things? https://www.ibm.com/blogs/internet-of-things/whatis-the-iot/;November 2016. Last Accessed: 17 August 2018.

[2] Lee I, Lee K. The Internet of Things (IoT): Applications, investments, and challenges for enterprises. Business horizons. - Amsterdam : Elsevier, ISSN 0007-6813, ZDB-ID 2226637. - Vol. 58.2015, 4, p. 431-440.

[3] Hassanalieragh M, Page A, Soyata T, Sharma G, Aktas M, Mateos G, Kantarci B, Andreescu S. Health Monitoring and Management Using Internet-of-Things (IoT) Sensing with CloudBased Processing: Opportunities and Challenges. 2015 IEEE International Conference on Services Computing (SCC), New York City, NY, USA, 2015, pp. 285-292. doi:10.1109/SCC.2015.47

[4] Aktaş F, Çeken C, Erdemli Y E. Biyomedikal Uygulamaları için Nesnelerin İnterneti Tabanlı Veri Toplama ve Analiz Sistemi. Tip Teknolojileri Ulusal Kongresi TIPTEKNO'14, 2014, pp. 299-302. (Son Erişim: 17 Ağustos 2018)

[5] Pang Z. Technologies and architectures of the Internet-of-Things (IoT) for health and wellbeing. M.S. thesis, Dept. Electron. Comput. Syst., KTH-Roy. Inst. Technol., Stockholm, Sweden, 2013.

[6] Islam SMR, Kwak D, Kabir MDH, Hossain M and Kwak K S. The Internet of Things for Health Care: A Comprehensive Survey. IEEE Access, Vol. 3, 2015; pp. 678-704.

[7] Akbulut Paklar F, Akan A. Akıllı Giyilebilir Hasta Takip Sistemleri. TIPTEKNO'15 Tıp Teknolojileri Ulusal Kongresi, 2015. (Son Erişim: 17 Ağustos 2018)

[8] Barnes K. Health wearables: Early days. PwC Health Standards, PwC Health Research Institute Report, 2014, https://www.pwc.com/us/en/health-industries/health-researchinstitute/publications/health-wearables-early-days.html (Last Access: 17 August 2018)

[9] Sağlam M, Güçlü M, İnce D, Savcı S, Arıkan H. Hipertansiyon ve Egzersiz, Hacettepe Üniversitesi, Sağlık Bilimleri Fakültesi Fizik Tedavi ve Rehabilitasyon Bölümü, Şubat 2008 (Son Erişim: 17 Ağustos 2018)

[10] Eryılmaz Ö, Kahraman İ, Şahin M. Kalp Hastaları İçin Bulut Bilişim Temelli Erken Uyarı Sistemi. Çanakkale Onsekiz Mart Üniversitesi Fen Bilimleri Enstitüsü Dergisi, 2016:2, 2, 01-19, (Son Erişim: 17 Ağustos 2018)

[11] Androis Studio, What's new? https://developer.android.com/studio/features/ (Last Accessed: 
17 August 2018).

[12] GitHub, https://github.com/ (Last Accessed: 17 August 2018).

[13] Bluetooth Low Energy, https:/learn.adafruit.com/introduction-to-bluetooth-lowenergy/introduction/ (Last Accessed: 17 August 2018).

[14] GATT Specifications, Blood Pressure Measurement, https://www.bluetooth.com/specifications/gatt/viewer?attributeXmlFile=org.bluetooth.char acteristic.blood_pressure_measurement.xml (Last Accessed: 17 August 2018).

[15] Firebase, https://firebase.google.com/docs/database/android/start/ (Last Accessed: 17 August 2018). 